\title{
Carnap's Legacy for the Contemporary Metaontological Debate
}

\author{
Matti Eklund \\ [Published in Blatti \& Lapointe (eds.), Ontology After Carnap, OUP 2016]
}

What is Carnap's legacy for the contemporary metaontological debate? Already a cursory examination of recent metaontological literature suggests that Carnap's influence has been great, when it comes to understanding what the relevant theoretical options are. Chalmers (2009), Price (2009) and Yablo (1998) all present Carnap as the hero for those dismissive of the enterprise of ontology; Hirsch (2005), Dorr (2005) and Sider (2001) all focus on specific views dismissive of ontology which they call Carnapian; Wilson's (2011) critical notice of Chalmers, Manley and Wasserman (2009) is largely focused on Carnap's influence.

I will here approach the issue of Carnap's legacy by bringing up a number of themes from Carnap and a number of themes from contemporary ontology - or rather, from contemporary metaontology - making a number of remarks on each, concerning the extent to the themes clearly from Carnap still are relevant today and the extent to which themes clearly central today really can be found in Carnap. In sections 1-3, I discuss theses arguably found in Carnap and the extent to which they are found in the contemporary debate. In sections 4-6, I discuss theses found in the contemporary discussion and discuss the extent to which they are found in Carnap. While the picture that emerges is somewhat nuanced, the overall conclusion can perhaps be summarized as follows: Carnap's importance for contemporary ontology is overstated; and to the extent that some contemporary themes are found already in Carnap, the contemporary discussions are just as problematic as Carnap's own discussions were.

\section{External and internal questions}

One Carnapian idea that is often referred to in the contemporary discussion is the distinction between external and internal questions. Let me first discuss how that distinction of Carnap's should be understood, and then discuss what contemporary metaontologists say. (The discussion to follow owes much to my (2009) and especially my (2013).)

Let me start with what should be uncontroversial. Carnap's view on ontology is somehow skeptical or deflationary: the questions which philosophers concerned with ontology have been concerned with are, somehow or other, non-questions. ${ }^{1}$ However, Carnap not only dismisses

\footnotetext{
${ }^{1}$ Carnap (1950), e.g. p. 207.
} 
ontological questions, but also presents a positive view of some sort concerning what ontological questions are like. Central to the positive view is a distinction between internal and external questions, and the notion of frameworks. ${ }^{2}$ Internal questions - questions internal to frameworks - including questions raised using the same forms of words as philosophers use to raise the ontological questions they are concerned with, are perfectly straightforward and non-problematic. External questions questions external to frameworks - are in bad standing, insofar as they are conceived of as genuinely factual. These questions can be taken to be all right, but only when they are taken as pragmatic questions.

Carnap's distinction between internal and external questions is a distinction between questions internal and external to frameworks; so in Carnap, the distinction is bound up with the notion of a framework. Somehow the problematic nature of external questions is related to their being external to frameworks. But what are frameworks supposed to be? Let me discuss two views on the matter that may with some justice be proposed.

First, there is the language pluralist interpretation. On the language pluralist interpretation, the 'frameworks' are simply languages, or language-fragments, and the only framework-relativity at issue is the familiar one of sentence-meaning to language. (One and the same sentence, non-semantically individuated, can have different meanings in different languages.) On this view, it is straightforward that there are frameworks; the main question rather concerns how appeal to frameworks can pack any sort of philosophical punch. On a second, relativist, understanding of Carnap's notion of a framework, 'frameworks' are not mere language-fragments; instead, frameworks are the sorts of things relativists appeal to - something like perspectives or outlooks. Framework-relativity is not the trivial dependence of meaning upon language. Instead, the propositions that the sentences express are not true or false absolutely but only relative to frameworks. The potential significance of appeal to frameworks is clear given the relativist understanding, but the ideas appealed to are obviously quite controversial.

On the language pluralist understanding of Carnap, the distinction between internal and external questions amounts to the following. Internal questions are questions raised using a particular language. The sentence "there are numbers", non-semantically individuated, is part of many different possible languages and its truth-value is relative to the language employed. We can also ask which language is the most useful to employ: this is a pragmatic external question. But it is clear why there can be no such thing as a factual external question: when the language pluralist insists that external questions understood as factual questions are non-questions, what she insists is simply that whenever we ask questions we do that using some language or other. One would only ask a factual external

${ }^{2}$ Carnap (1950), pp. $206 \mathrm{ff}$. 
question if, absurdly, one attempted to stand outside of language. On the relativist interpretation, the picture is the following. An internal question is a question of what is true relative to some framework in this demanding sense of 'framework'. An external question is a question of what framework is the correct one. The relativist holds that this question lacks an answer if understood as a question about matters of fact. What can be meaningfully asked is which framework is more useful for a given purpose. Given the relativist interpretation of 'framework', there can genuinely be both platonist and nominalist frameworks.

To further illustrate the difference between language pluralism and relativism, consider the application of these views to the dispute between platonists and nominalists. The language pluralist may stress that sentences that are the focus of ontological controversy, such as "there are numbers", will come out true in some possible language and false in another, and that the decision to affirm this sentence can be bound up with the decision to use this possible language. In some sense there are platonist and nominalist languages. But the 'in some sense' is important, for it is not as if platonism the proposition that there are abstract entities - comes out true in some languages and untrue in others. The truth-value of a proposition, as opposed to a (non-semantically individuated) sentence, does not vary from language to language. Of course talk of languages as platonist and nominalist must then be treated with a large pinch of salt, and it is not immediately clear why there being platonist and nominalist languages in this obviously attenuated sense should be thought relevant to anything. By contrast, the relativist can speak of genuinely platonist and nominalist frameworks. A platonist framework is one relative to which the propositions that express platonism are true and a nominalist framework is one relative to which the propositions that express nominalism are true.

As already stressed, the central claims of language pluralism are rather trivial. How can they even be relevant to skepticism about ontology? Obviously language pluralism needs to be supplemented to be so relevant - but how exactly? Here is one suggestion. Carnap's criticism of ontology can perhaps be understood as follows: While 'there are'-questions can be sensibly raised, and answered, within various languages, ontologists approach their questions in such a way that they must be understood as raising external questions and treating them as factual, even while factual external questions fail to make sense. Here is an illustration, using the same example as earlier. Suppose one of us speaks a language where "there are numbers" is true and the other speaks a language where "there are numbers" comes out false, and that we come to find out that it is so. Then I go on to say "OK, 'there are numbers' comes out true in my language and false in yours. But, language-independently, are there numbers?". This would be odd. What could this supposed further question amount to? Of course, if F-discourse is about something language-independent, and "there are Fs" comes out true in my language, then so does "language-independently, there are Fs". Imagining that there is a further question there, not trivially answered by what has already been established, would be confused. 
Carnap's charge could be that ontologists are trying to ask this wrong-headed question. The only 'further' question here is a pragmatic one: which language is it, for certain practical purposes, best to use? ${ }^{3}$ That is a pragmatic external question. For future reference, let us label questions like the supposed further question confused questions. For the envisaged criticism of ontology to be effective it would of course have to be shown that the questions ontologists ask really are confused questions in the sense characterized. It is not clear how plausible this is, or how one might go about arguing the point. Just to make clear the relation between different points here: On the language pluralist interpretation, Carnap's 'frameworks' are language-fragments. Moreover, the framework-relativity (that is, ordinary language-relativity) of ontological sentences is, somehow, central to a critique of the ontological enterprise. I have further presented one critique of ontology - the critique that ontological questions are confused questions - for which the framework-relativity of ontological sentences is thus central. But I don't take language pluralism to be committed to this particular way of criticizing the enterprise of ontology.

I think that if indeed some sort of appeal to framework-relativity is central to Carnap's view on ontology (as I will get to shortly, there are complications), we obviously face the question of what the frameworks are, and while there are other questions to be asked, all interpretations will make Carnap a language pluralist or a relativist. Either way something quite radical, and quite distinctive to Carnap, is going on. I also think that of the two interpretations discussed, the language pluralism interpretation is much more reasonable than the relativist one. ${ }^{4}$

How does Carnap's actual external/internal distinction compare with the allusions to this distinction in the contemporary ontological debate? In his (2005), Thomas Hofweber prominently refers to this distinction in the course of his distinction between two types of quantification and two types of uses of singular terms, and his own view is explicitly modeled on Carnap's. The idea is that the internal questions are those used raised using 'internal' - roughly, substitutional - quantification, and names used 'internally' rather than used to attempt to refer to external objects. External questions are raised using 'external' - roughly, objectual - quantification, and named used to attempt to refer to external objects. Stephen Yablo's seminal (1998), arguing for a certain kind of fictionalism, understands 'internal' questions as questions asked about what's true in the pretense and 'external' questions as questions about what is literally true. When presenting the metaontological map as he

\footnotetext{
${ }^{3}$ In the text I speak of questions over which sentences are true. One may then want to object that when we are concerned with the existence of numbers, we are concerned with the proposition that there are numbers. However, focusing on propositions changes nothing essential. Corresponding to the different languages there are the different propositions expressed by the different sentences. Saying "OK, we know that the proposition expressed by 'there are numbers' of one language is true and the proposition expressed by 'there are numbers' of the other language is false - but is it really the case that there are numbers?" does not sound very good either.

${ }^{4}$ For further discussion of which interpretation is more reasonable, see my (forthcoming).
} 
sees it, David Chalmers (2009) accords pride of place to Carnap, saying that on Carnap's view there is no fact of the matter as to what is true outside of a framework and takes this as his main model of ontological antirealism. More generally, Chalmers draws the following distinction and does so with reference to Carnap:

An ordinary existence assertion, to a first approximation, is an existence assertion of the sort typically made in ordinary first-order discussion of the relevant subject matter. For example, a typical mathematician's assertion of 'There are four prime numbers less than ten' is an ordinary existence assertion, as is a typical drinker's assertion of 'There are three glasses on the table'.

An ontological existence assertion, to a first approximation, is an existence assertion of the sort typically made in broadly philosophical discussion where ontological considerations are paramount. For example, a typical philosophers' assertion of 'Abstract objects exist' is an ontological existence assertion, as is a typical philosophers' assertion of 'For every set of objects, there exists an object that is their mereological sum'. ${ }^{5}$

And he notes that for many theorists writing about ontology, a distinction like this is crucial. Chalmers refers to Dorr (2005), Hofweber (2005), Horgan (2001), and Yablo (2000). One might add a number of others, including for example Sider (2009) and Cameron (2010).

The distinction that Carnap himself draws between external and internal questions is not very clearly related to the distinctions one finds associated with Carnap in the literature. The general idea that many authors skeptical of the enterprise of ontology have found appealing is that there are two importantly different ways of taking questions of the form "Are there Fs?", "Do Fs exist?", etc. On one understanding, they are clearly tractable but not of relevance to what ontologists are concerned with. On another understanding they are properly ontological, but their tractability is something that can be questioned. We find versions of this in, e.g., Hofweber and Yablo. Call this the General Distinction. Theorists not dismissive of ontology often draw a similar distinction: on one understanding the questions are tractable - indeed easily resolvable - but of no concern to ontology; on another, they are harder but still in principle tractable, and the proper domain of ontology. Sider and Cameron present versions of this.

If Carnap's contribution was just to call attention to the General Distinction, his contribution would hardly be original. Surely others before him had in other terms called attention to similar distinctions, for example when talking about distinctions between loose talk and what is strictly speaking true or between speaking with the vulgar and thinking with the learned. And

${ }^{5}$ Chalmers (2009), p. 81. 
Wittgensteinian reminders about how in philosophy language goes on holiday would be as relevant for the contemporary metaontologist as Carnap's discussion. ${ }^{6}$ The specific appeal to Carnap would be misleading.

As we have seen, no matter how Carnap's distinction between internal and external is best understood, it involves something more specific. On either of the two interpretations mentioned Carnap has something much more specific in mind than the General Distinction, and something that contemporary ontologists are not concerned with. This is most clearly so given the relativist interpretation, for adherence to relativism goes beyond the General Distinction, and beyond what participants to the contemporary debate commit to. But I would say that also on the language pluralist interpretation, this is so. One complication, however, is the following. As already stressed, one must keep in mind that if frameworks are just languages, then it is not immediately obvious just how appeal to framework-relativity can be central to a critique of ontology. Somehow, language pluralism must be supplemented. Maybe Carnap was a language pluralist and whatever he supplemented it with to reach anti-ontological conclusions is something also found in the contemporary debate. I have presented one suggestion concerning what the supplementary assumptions might be - the appeal to confused questions, above - and if that suggestion is right as interpretation of Carnap, again Carnap is concerned with something that plays no role in the contemporary debate. But that suggestion was only tentative. For all I have said so far, one can think that there are other ways of elaborating on the basic language pluralist idea, such that there after all is an important continuity between what Carnap on the language pluralist interpretation can be taken to hold and what contemporary ontologists are concerned with. Later, when discussing semanticism and when discussing quantifier variance, I will return to this idea, and reject it.

\section{Analyticity}

Another striking feature of Carnap's view, e.g. in (1950), is that he holds that many positive ontological claims are analytically true, and he also holds a view on analyticity on which analytic truths are somehow vacuous or metaphysically trivial. The emphasis on analyticity provides an alternative route to a certain kind of skepticism about the ontological enterprise. The reason ontological inquiry into whether - say - numbers exist is silly is that it is vacuously true that numbers exist. "Numbers exist" is true but does not impose any demand on reality. Investigating whether reality meets the demand that this sentence imposes on it is misguided, for there is no such demand.

Of course, merely saying that some positive ontological claims are analytically true does not vindicate wholesale skepticism about ontology. At most what it vindicates is that in cases where the

\footnotetext{
${ }^{6}$ Wittgenstein's Philosophical Investigations, section 38.
} 
claims at issue are analytically true or false, the enterprise is deflated. One could get to wholesale skepticism if one could argue that all ontological claims are analytically true or false. But even someone as liberal about analyticity as Carnap might balk at the claim that it is analytic that there are physical objects, let alone the claim that it is analytic that there are tables and chairs. Another, more plausible, way to get to wholesale skepticism via appeal to analyticity would involve saying that the distinctly philosophical part of an ontological dispute always turns out an analytically true or false claim. Carnap might hold that even if it is not analytically true that physical objects (or tables) exist, it can be analytically true that if such-and-such sense data obtain then physical objects (or tables) exist. The antecedent is not analytic; but neither is it something for philosophers qua philosophers to weigh in on.

One thing to note about this analyticity-driven skepticism about ontology - call it analyticism - is that it seems entirely separable from any appeal to an external/internal distinction. So if Carnap can be said to have subscribed to analyticism, why did he also emphasize the external/internal distinction? Here is one possible answer to that question. An immediate objection to analyticism is that surely ontological questions are not that trivial, as demonstrated by the difficulties that ontologists dealing with them get into. To that objection, Carnap can be thought of as responding: the internal questions - the only sensible questions in the vicinity - are analytic; the difficulties that ontologists get into arise when they try to ask confused, external questions. When it seems to us that ontological questions both make sense and are difficult, we are conflating two types of questions, one type which make sense, and one which is difficult. ${ }^{7}$

Whatever the role of analyticity in Carnap, what is the role of analyticity for contemporary skepticism about ontology? Appeal to analyticity has lost some of its allure since Carnap's time. While reasonably many authors are still, after Quine, happy to speak of analytic or conceptual truths or entailments, few would assign to analyticity the central role it seems to have had for Carnap and some of his positivist contemporaries. However, one prominent exception to this trend is Amie Thomasson (e.g. 2007). Let me criticize at some length what she says about analyticity. The problems that Thomasson's discussion faces are general: they are of importance for anyone who seeks to appeal to analyticity in an attempt to debunk ontology.

Thomasson appeals to how truths about ordinary objects (e.g. tables) are analytically entailed by truths about more basic objects and their relations (e.g. simples arranged tablewise) in order to deflect skepticism about ordinary objects; and at a metaontological level she seeks to replace the dominant ontology as a substantive inquiry with a conception wherein conceptual analysis plays more of a role. Let me explain her strategy as applied to the problem of causal overdetermination. The

\footnotetext{
${ }^{7}$ Compare here Carnap (1950), p. 209.
} 
supposed problem is that where, intuitively, we would say that a window is shattered by a baseball, it is true to say that the window is shattered by the simples arranged baseballwise, and to posit baseballs in addition to these simples is to say, implausibly, that the event of the window's shattering was causally overdetermined. Thomasson's response is to say that the existence of the baseball is analytically entailed by the existence of the simples arranged baseballwise. If this is the case, Thomasson says, the existence of the baseball does not "require anything more of the world" than the existence of simples arranged baseballwise does, and then "there is no doubling of or competition between the two claims". ${ }^{8}$

Now, it has become common in discussions of analyticity, since Paul Boghossian's seminal (1996), to distinguish between on the one hand the metaphysical idea of analyticity - the idea of vacuous truth or truth by virtue of meaning - and on the other hand the epistemological idea of there being sentences we are somehow justified in accepting solely by virtue of linguistic competence. Given this distinction, it is plain that one can in principle subscribe to one without subscribing the other. Boghossian defends the idea of epistemic analyticity while rejecting that of metaphysical analyticity. Thomasson's point about the qua problem in the first instance shows that something about the competence of speakers helps determine reference: appeal merely to causal relations is not enough to determine reference. ${ }^{9}$ The discussion of the qua problem in the first instance promises to say something about competence and hence epistemic analyticity. But what she needs for what she says about causal overdetermination is metaphysical analyticity. How does she get to that? Relevant remarks here are the following:

....analytic claims are illustrations of constitutive rules of language use. But rules are just disguised...commands, so insofar as they are used as illustrations of [these rules], analytic claims should not be understood as reports of or assertions of anything, and thus not as expressions apt for truth of falsehood. Instead, with their rule-demonstrating force, they should be understood as something like a converted command, much as demonstrations of the proper way to dance the merengue... ${ }^{10}$

The sense in which analytic claims seem to be about the world is that they are stated in the object-language.... But there is another perfectly good sense in which they "say nothing" about

\footnotetext{
8 Thomasson (2007), p. 16.

${ }^{9}$ See Devitt and Sterelny (1987) for a classic presentation of this problem.

10 Thomasson (2007), p. 69.
} 
the world and are "entirely devoid of factual content"....The sense is that-if we do treat them as true- it is clear that their truth does not depend on any empirical fact's obtaining. ${ }^{11}$

The truth of the analytic claim, taken as a genuine description....is guaranteed given the relations in the rules of use for the terms employed....though the adoption of these rules is not a truthmaker for the claim (it only establishes the meaning of the terms involved and the truthconditions for each part). This also makes sense of the idea that the truth of analytic claims....is independent of all empirical facts_-even of there being bachelors or men, or indeed anything at all. ${ }^{12}$

There are a number of different ideas suggested by these passages. In the first passage, Thomasson seems to suggest that analytic sentences are not truth-apt at all, being merely disguised commands. I am not sure how wedded she really is to this idea. But it seems problematic. Is she saying that it isn't true that all bachelors are unmarried? Are there no logical truths? And won't Frege-Geach problems arise for the proposal? How can it be that analytic sentences embed in the way that ordinary indicative sentences embed? How can they occur in valid arguments in the way that ordinary indicative sentences occur in valid arguments? Maybe some utterances of analytic sentences are, as Thomasson says, to be understood more as instructions or commands, but even so, that should not to be taken to mean that analytic sentences do not semantically express truth-evaluable propositions. Focus then on what other ideas are found in these passages. A point made in the two last passages quoted is that the truth of the analytic sentences is independent of any empirical fact's obtaining. But emphasizing this is just a mistake. For this holds of all necessary truths, and a characterization of analytic truth had better distinguish between analyticity and necessity. ${ }^{13}$

Thomasson tends to speak of analytic "claims" rather than "sentences". For some purposes it might have been better to speak of sentences, and uses of sentences. The reason is that there are two theses in the vicinity that must be distinguished. One thesis is that analytic sentences, while in the indicative, have the same type of meaning as overtly prescriptive sentences - imperatives. Another thesis is compatible with analytic sentences having the same type of meaning as ordinary indicative sentences, and says only that they tend to be used to do what imperative sentences are used to do. If Thomasson's thesis is the former, then, as mentioned, problems familiar from discussions of other

11 Thomasson (2007), p. $69 \mathrm{f}$.

12 Thomasson (2007), p. 70.

13 Thomasson does believe in an analytic theory of necessity (with provisos necessary to accommodate a posteriori necessities); see especially her (2007a). But that does not make the criticism misplaced. It is one thing to explain all necessities by appeal to the claim that they really are analytic truths; another to just use "analytic" to mean what others use "necessary" to mean. Thomasson's aim is to do the former; the charge is that what she actually does is the latter. 
non-factualist theses arise. These questions may have good answers. But they are serious questions, and Thomasson's discussion doesn't help answer them. If Thomasson's thesis instead is the latter, then her thesis avoids these problems. But thus understood her thesis is compatible with analytic sentences expressing truths, and thesis does not directly address what sorts of truths analytic sentences semantically express. It only says that the sentences are often not used to state the truths they semantically express but are used for other purposes.

A different idea concerning metaphysical analyticity is found in the third passage above: some sentences are analytically true because the associated rules of use guarantee that they are true. But consider a criticism Boghossian makes of the metaphysical notion of analyticity. Boghossian argues that for any sentence $S, S$ is true iff, for some proposition $p, S$ means that $p$ and $p$. The meaning of $S$ can only help with what proposition is the meaning of $\mathrm{S}$, not with the second condition, that this proposition be true. ${ }^{14}$ For all Boghossian says, there can be sentences that are guaranteed by the rules of use to express true propositions: it can be that it is guaranteed that the sentence will express some true proposition or other. But this alone is not enough to legitimize the notion of truth by virtue of meaning. Focusing on how rules of use can guarantee that an analytic sentence expresses some true proposition is beside the point. The real question concerns what the explanation of the truth of the proposition being expressed might be.

In her (2007a) - published in (2010) - Thomasson has returned to issues surrounding analyticity and necessity. But that discussion faces similar problems. In a central passage, Thomasson says,

...consider the analytic claim: "All bachelors are men," or more formally, " $\forall \mathrm{x}(\mathrm{Bx} \rightarrow \mathrm{Mx})$." The corresponding rule of use is: "apply 'bachelor' only where 'man' applies," so the truth-conditions for "there is a bachelor" include that there is a man. This guarantees that if there is something that is a bachelor (i.e. to which 'bachelor' applies), then there is something that is a man (i.e. to which 'man' applies). This ensures the truth of the conditional for any substitution instance, for if the antecedent is true, the consequent is guaranteed to be true, given the relations in the rules of use for the terms employed. But actual bachelors and their features are not truth-makers for the claim, for the analytic claim is guaranted to be true regardless of any features of the world: it is vacuously true even if there are no bachelors whatsoever...Indeed, even if there is nothing in the world at all... the conditional claim...is true. This gives us a clear way of understanding why analytic claims are guaranteed to be true in a truth-conditional sense, independently of all facts about the world. ${ }^{15}$

${ }^{14}$ Boghossian (1996), p. 364.

15 Thomasson (2007a), p. 148. Again there is the talk of "analytic claims". 
First, there is the seeming equivocation between on the one hand speaking of analytic truths as guaranteed to be true and on the other hand speaking of analytic truths as vacuously true, or true independently of "all facts about the world". Some pronouncements seem true of all necessary truths, on any view on metaphysical necessity. All necessary truths are true regardless of what contingent facts obtain. Others suggest the more distinctive claim that analytic truths are vacuous. As against that claim, Boghossian's argument, reproduced above, is relevant. Second, the reasoning with which Thomasson begins only establishes that "all bachelors are men" is true since "all men are men" is, and that whatever the explanation is of why the latter sentence is true also explains why the former is true. Thomasson does not explicitly discuss "all men are men". If, somehow, it is vacuously true, maybe "all bachelors are men" is so too. But if it is made true by general logical features of the world, then "all bachelors are men" is made true by those same features. ${ }^{16}$

\section{Empiricism and verificationism}

Carnap's stance on ontological questions was clearly influenced by his empiricism and his verificationism. One reason why his (1950) is as unargumentative as it is, is presumably that Carnap is writing it for an audience that he expects to share these views, and the attendant skepticism toward ontology. He doesn't defend skepticism about ontology per se so much as defend the propriety of speaking in a way which seems 'ontological', even in the face of such skepticism.

Few authors today would say, "I am an empiricist and hence I am skeptical of ontology...”; still fewer would say, “I am a verificationist and hence I am skeptical of ontology...”. But one can still find these themes in the works of contemporary authors skeptical of ontology. Take first Eli Hirsch. The views associated with Hirsch will be more properly discussed in the next couple of sections. But briefly and roughly, one main thesis he defends is that in apparent ontological disputes, the disputants speak past each other. Given the principle of interpretive charity, the best way for me to translate an opponent involves using a 'conciliatory' translation scheme given which the opponent does not state anything that conflicts with what I say. In his (2009), John Hawthorne asks the pointed question of why one should not say the same in the case of theorists defending empirically equivalent empirical theories. Surely one can devise conciliatory translation schemes also in such cases, but such translation schemes would generally be taken to be incorrect - and as Hawthorne

\footnotetext{
16 Thomasson (2007a, p. 146) is explicit that she does not present an account of logical necessity. But my point is that since she does not do so, she does not show that "all bachelors are men" expresses something vacuously true. (I also want to add a remark on the example. Thomasson makes her point using a universal generalization, and if there are no bachelors there is a sense in which the sentence is 'vacuously' true. Thomasson seems to want to use this to support her view on analytic truths. But this should not be taken to be a compelling argument for taking analytic, or generally necessary, truths to be vacuous, for example because "all bachelors are tidy", surely a synthetic sentence, is also such that if there were nothing at all in the world, it would be true.)
} 
stresses, Hirsch would not disagree. ${ }^{17}$ But how can Hirsch treat the cases differently? As Hawthorne mentions, Hirsch stresses the apriority and necessity of ontological claims, and Hawthorne says, "[Hirsch's] idea seems to be that we should, in translation, give special respect to claims that communities regard as a priori and necessary, and that this lends itself to conciliatory translation schemes in the case of endurantists and perdurantists but not in the case of those empirically equivalent theories where the relevant bits of theory are not regarded as a priori and necessary". ${ }^{18}$

Why does Hirsch think that claims regarded as a priori and necessarily true have this special status? Here is a natural hypothesis: while Hirsch does not speak of analyticity he is thinking of a priori necessary truths as analytic, and that is why he thinks what he does. Underlying what Hirsch says is an aversion to the idea of substantive a priori truths.

Let me elaborate. Hirsch stresses that charity in interpretation involves not taking the interpretee to reject what one finds obvious. This means according a special status to the truths one regards as a priori and necessary, if one takes these truths to be obvious. There are certainly different possible reasons one might have for taking them to be obvious. But one very prominent kind of view on which such truths have this kind of status is one on which they have such a status because of being analytic.

This hypothesis about Hirsch receives support from other aspects of his debate with Hawthorne. Hawthorne argues, against Hirsch, that contemporary metaphysicians do not regard their theses as a priori but defend them "on the grounds of broad theoretical virtues like simplicity, reasonable conformity with common sense, and so on"; they thus, Hawthorne says, regard their theses as "quasi-empirical" ones, "whose tenuous connection to experience is not different in kind to that of various bits of high-level physical theory". ${ }^{19}$ Hirsch's (2009) reply is basically that whatever rhetoric metaphysicians may use, their actual arguments are paradigmatically a priori arguments. $\mathrm{He}$ comments, " ... what Hawthorne must mean is that revisionary ontologists often adopt the speculative tone of high-level theorists rather than the tone of philosophers engaged in straightforward conceptual or linguistic analysis. That may well be, but their main arguments, whatever their speculative or theoretical tone, are a priori rather than empirical". ${ }^{20}$ What is striking is that Hirsch contrasts being speculative or theoretical with being a priori. ${ }^{21}$

\footnotetext{
${ }^{17}$ Hawthorne (2009), p. 214 f.

18 Hawthorne (2009), p. 217.

${ }_{19}$ Hawthorne (2009), p. 217.

${ }^{20}$ Hirsch (2009), p. 233. In his contribution to the present volume, Hirsch presents other replies to Hawthorne's points. My aim here is not to adjudicate the Hirsch-Hawthorne dispute but to highlight an underlying assumption about the a priori.

${ }^{21}$ Hawthorne too contrasts the two, and one can also ask on what basis Hawthorne does this. (Does the fact that mathematics is speculative and that appeal to theoretical virtues play a role in mathematics contradict the claim that mathematics is an a priori science?)
} 
Earlier I discussed Thomasson's reliance on analyticity. There are also other ways in which Thomasson reasons like a rather traditional empiricist. Central to the metasemantic outlook that is at the heart of her deflationary metaontology is the idea that sortals come with "frame-level application conditions", and that to see whether there are tables all one needs to do is to consider whether these frame-level application conditions are satisfied. The idea is that this is straightforward, so that doubts about whether there really are tables can be set aside. In connection with this she emphasizes that it is an empirical and not a philosophical issue whether the application conditions are fulfilled. ${ }^{22}$ While Thomasson does not explicitly invoke traditional empiricism, it helps explain how she reasons if we take traditional empiricism to be in the background: there is the 'analytic' question of what the application conditions associated with a given expression are and then the 'empirical' question of whether these conditions are fulfilled. Anyone who is more friendly toward a substantive a priori or who finds the a priori/empirical distinction less clear-cut will naturally be less friendly toward this assumption.

Insofar as skepticism about ontology is driven by traditional empiricist concerns about ontology, the skepticism generalizes to other areas of philosophy. A traditional empiricist can agree that a priori inquiry is all right so long as it is supposed to issue only in analytic truths but be skeptical about those areas of philosophy that seem to be a priori even while the conclusions on the face of it seem like they cannot be analytic. For any such area, she would have to deny the appearance that the inquiry is a priori, or reject the whole inquiry as confused, or say that the conclusions are analytic, contrary to appearances. This all applies to, say, ethics as much as it applies to ontology.

In sections 1 through 3 I have discussed some themes found in Carnap and discussed how they relate to what is going on in contemporary ontology. In the following sections I will discuss some themes found in contemporary ontology and discuss how they relate - or not - to Carnap.

\section{Verbal disputes}

Hirsch, probably the main contemporary skeptic of ontology, is often called "neo-Carnapian", and Hirsch himself has occasionally referred to Carnap as an ally. ${ }^{23}$ (In his contribution to the present volume, Hirsch adds nuance by talking about "three degrees of Carnapian tolerance".) There are two theses centrally discussed in the contemporary literature that both are associated with Hirsch. ${ }^{24}$ One is that ontological disputes are merely verbal; one is that our concept of existence is in no way

\footnotetext{
22 See Thomasson (2007), e.g. p. 195.

${ }^{23}$ For relevant passages in Hirsch, see the early pages of his (2005) and his (2008). For relevant references in other writers, see, e.g., Barnes (2009); Båve (2011), p. 104; Beebee, Effingham \& Goff (2011), p. 125 (entry on Metametaphysics); and Hawley (2007), p. 237.

${ }^{24}$ Note the cautious formulation. Hirsch's own views are rather subtle. I discuss how best to understand Hirsch in my (2011). For the purposes of comparing Carnap and the theses discussed in contemporary metaontology, it is more reasonable to focus on the general theses.
} 
metaphysically privileged but is merely one among a number of different possible concepts of existence, none of which is privileged. In this section I will focus on the former claim, which, following Karen Bennett (2009), I will call semanticism.

There is a significant unclarity in the claim that "ontological disputes are merely verbal", one which remains even if we take it to be clear what it means for two particular speakers to engage in a verbal dispute. Once we resolve this unclarity it should no longer seem attractive to criticize the enterprise of ontology in the way envisaged. Focus on a dispute that a semanticist might characterize as "merely verbal"; say, the dispute between mereological nihilists, denying the existence of complex objects, on the one hand and friends of ordinary objects ("commonsensists", let us call them) on the other. What might a semanticist mean in so characterizing it? Here are three different claims that could be made: (a) Looking at what actual nihilists and commonsensists actually say, it turns out that these actual theorists are merely speaking past each other, and have a verbal dispute. (b) For quite general reasons, nihilists and commonsensists, actual and hypothetical, will tend to speak past each other. (c) Nihilists and commonsensists for principled reasons always speak past each other. ${ }^{25}$

If the semanticist's claim were (a), then although her claim would be significant - she would show certain debates as actually prosecuted to be misguided - it wouldn't be of principled significance: ontologists could in principle avoid these problems even if many contemporary ontologists fall afoul of them. Even if, say, Peter van Inwagen and David Lewis actually speak past each other, for instance because one of them fails to use "there are tables" with the meaning it actually has in English, there certainly can for all that be more careful counterparts of them, both using 'there are tables' with its actual meaning, and having a dispute about whether the sentence thus understood is true. It is certainly of interest if main figures in ontological debates speak past each other, but as no reason has been given for thinking that there cannot be non-verbal ontological debates, no argument has been given to the effect that ontological disputes as such are not genuine. ${ }^{26}$

Similar remarks apply to (b). To illustrate this, let me first take an example from elsewhere, the debate over which logic is the right logic. If someone - call him Graham ${ }^{27}$ - keeps assertively uttering sentences that when homophonically interpreted express something which we take to be obviously logically false (say, sentences of the form "S and not S"), then all else equal, there is (by 'charity') good reason to take him to mean something different by these sentences than we do. And this

${ }^{25}$ If the semanticist is right, then it is of course wrong to speak of 'nihilists' and 'commonsensists' this way. What we have are those who say "there are no ordinary objects" and those who say "there are ordinary objects", but the claim that the former hold that there are no ordinary objects and the latter hold that there are ordinary objects is precisely what is problematized. That said, in the main text I will for simplicity speak of 'nihilists' and 'commonsensists'.

${ }^{26}$ Hirsch's view is not actually that no ontological disputes are genuine. The relevant claim in the context of discussion of Hirsch is rather that certain ontological questions are such that there can be no genuine disputes over them.

${ }^{27}$ Compare Priest $(1987 / 2006)$. 
generalizes beyond logic. As for instance Quine has stressed, generally, if our interpretation of someone takes her to be making assertions that are obviously false, then that is an important piece of evidence against the interpretation. This can in principle be used as an argument for why ontological disputes tend to be verbal. If one can also argue that the propositions expressed by the sentences fought over in ontological disputes are obviously true or false, one can argue that someone with a different view on one of these sentences should, all else equal, be taken to mean something different by it than what we do. ${ }^{28}$

I'm only presenting this in broad outline. Both the principles of interpretation and the claims about the obviousness of ontological sentences can certainly be challenged. But never mind, for this is all beside the point anyway. Suppose, for argument's sake, that the argument outlined works. Still, all it creates is a defeasible presumption that a given ontological dispute is merely verbal. For all that the argument shows, someone who assent (dissents) to sentences (pertaining to logic or ontology or what have you) that we take to express something obviously true (false) might still mean the same as we do by these sentences. Perhaps, if Graham not only says things of the form "S and not S", but goes on to say, e.g., "I know it sounds odd. It is counterintuitive to me too; or at least it was so at first. But we're simply forced to accept some of these claims. For consider the following paradox $[\ldots]$ In light of this we have to give up some central and cherished belief, and I think, more specifically, that we must give up the belief that there are no true sentences of this form”. That might help tip the scales in favor of a homophonic interpretation. So long as it is possible for the scales to be thus tipped, it is possible to have a non-verbal dispute over which is the right logic. Analogous remarks apply in the case of ontological disputes. This brings us to (c), roughly, the view that it is impossible to have a dispute over the propositions expressed by ontological sentences: that whenever, both in actual and in hypothetical scenarios, it appears that two people have a disagreement over one of these propositions, that appearance is deceiving. That claim would be significant. But it is an implausibly strong claim, as should be agreed on all hands. Even in the case of logic, and someone apparently denying basic logical truths, it is implausible that appearances always are deceiving.

So, to sum up: neither (a) nor (b) is strong enough to show that ontology per se, as opposed to particular token disputes between particular theorists, is to be dismissed; and (c) is implausibly strong. (a)-(c) seem to exhaust the relevant alternatives. So there is no interesting yet prima facie plausible claim to the effect that ontological disputes are non-substantive for the reason that they are merely verbal. (Again to stress, claims like (a) and (b) are themselves radical claims, and claims that promise

28 In his (1948), Quine stressed the obviousness of basic ontological claims. This together with Quine's claim about correct interpretation yields semanticism (with the caveat that the claim about ontological sentences is from earlier work than the claims about interpretation). This is interesting in light of Quine's status as someone who rehabilitated ontology as a serious enterprise. (I wouldn't put too much theoretical weight on the point, but there is an element of irony to it.) 
to be of some importance. It is their significance as far as the principled criticism of the enterprise of ontology is concerned that I am skeptical of.)

I have discussed semanticism without attention to what Hirsch actually says. The excuse for that is that my criticism is principled, and not tied to any particular way of elaborating upon the basic semanticist idea. ${ }^{29}$ But it may anyway be useful to consider what Hirsch says. While Hirsch tends not to be explicit about whether he has in mind something like (a) or like (b) or like (c), or if there is some other alternative that he has in mind, it is easy as a reader to get the sense that of the alternatives mentioned, (c) is closest to what Hirsch is after given that he aims for a principled criticism. But when Hirsch makes remarks directly related to the issue I'm here bringing up, what he says is,

Lewis points out that a stage seems eventually to be reached in ontology when "all is said and done", when "all the tricky arguments and distinctions have been discovered", so that each position has achieved a state of "equilibrium". I am thinking primarily of this stage when I say that the dispute between endurantists and perdurantists is verbal. Prior to this stage, if an endurantist, say, is disposed to change her mind in response to some perdurantist arguments, then charity to use may favor interpreting her language as P-English, so that the change of mind is deemed reasonable and her earlier judgment deemed mistaken. But after the "all is said and done" stage has been reached, there is nothing to be said but that each side speaks the truth in their own language. In saying this I am rejecting Lewis's claim that when we have reached the "all is said and done" stage we are left with a "matter of opinion" in which one side "is making a mistake of fact". 30

What Hirsch seems to be saying is that his thesis is only that if an endurantist and a perdurantist - to stick with that example - would disagree even at the "when all is said and done" stage then their debate is merely verbal. But if Hirsch is really only concerned with debates that would remain at the "when all is said and done" stage, then it just isn't clear how what he's talking about applies to metaphysical debates as actually prosecuted. In order to show that actual metaphysical debates would remain at the "all is said and done" stage he would have to show that the disputants do not allow the same evidence as relevant, even when they are in possession of all the facts. But showing that is a tall order. How can one even reasonably go about that task? It is not sufficient to show that the disputants actually rely on different evidence. Second, to relate back to the remarks above on (a) and (b), even if all those who actually seem to disagree with me on ontological matters are such that our dispute would remain

${ }^{29}$ Besides, as already noted, Hirsch's own position is rather complex. See my (2011) for further discussion. ${ }^{30}$ Hirsch (2009), p. 241. 
at the all-is-said-and-done stage, and hence by Hirsch's reasoning our disagreement is merely verbal, it could still be that some possible opponent is such that we would agree at the all-is-said-and-done stage, and hence our disagreement is genuine. But can Hirsch then be thought to have a principled point against the enterprise of ontology?

I have discussed three possible precisifications of "ontological disputes are merely verbal". On the two first, the claim may be plausible but doesn't have the generality required to undergird a dismissive attitude toward ontology. On the third, the claim just isn't plausible. Accordingly, one cannot justify a dismissive attitude toward ontology by appeal to the idea that ontological disputes are verbal. Semanticism is not a good idea, if one seeks to present a principled critique of the very enterprise of ontology. But was Carnap a semanticist? Not in (1950). The topic of verbal disputes is not brought up there. The closest Carnap comes to discussing it is in this passage:

Suppose that one philosopher says: "I believe that there are numbers as real entities. This gives me the right to use the linguistic forms of the numerical framework and to make semantical statements about numbers as designata of numerals". His nominalistic opponent replies: "You are wrong; there are no numbers. The numerals may still be used as meaningful expressions. But they are not names, there are no entities designated by them. Therefore the word 'number' and numerical variables must not be used..." I cannot think of any possible evidence that would be regarded as relevant by both philosophers, and therefore... would decide the controversy or at least make one of the opposite theses more probable than the other...Therefore I feel compelled to regard the external question as a pseudo-question, until both parties to the controversy offer a common interpretation of the question as a cognitive question; this would involve an indication of possible evidence regarded as relevant by both sides. ${ }^{31}$

Here Carnap brings up how the platonist and the nominalist would not regard the same evidence as relevant for settling the question. A natural further thought might have been: so the platonist and the nominalist are considering different questions. But that is not what Carnap goes on to say. He seems rather to think that the Platonist and the nominalist are concerned with the same thing - the external question - but what they are concerned with is a pseudo-question. He says "I feel compelled to regard the external question as a pseudoquestion" and seems to refer to the question supposedly at stake by "the external question".

There may however be reason to think that in his earlier (1935), Carnap is more sympathetic to the idea that ontological disputes are merely verbal. He there emphasizes the "language-relativity" of

${ }^{31}$ Carnap (1950), p. 219. 
philosophical theses. More specifically, he promotes the practice of always, when stating a philosophical thesis, being fully explicit about what language one is using. The reason this would be useful is that participants to philosophical disputes are apt to use different languages, without being aware that they are. Carnap brings up a hypothetical dispute between two philosophers. One of them says "numbers are classes of classes". The other says "no, numbers are primitive objects, independent entities". ${ }^{32}$ Carnap says that the theorists should first transpose their thesese into formal mode. The former theorist then says "numerical expressions are class-expressions of the second order" and the latter says "numerical expressions are not class-expressions, but elementary expressions". ${ }^{33}$ But stated that way, Carnap says, the sentences are not complete: it must also be stated which languages they concern. When completed, the sentences would read something like "in L1, numerical expressions are class-expressions of the second order" and "in L2, numerical expressions are not class-expressions, but elementary expressions". ${ }^{34}$ But then it is clear that the assertions are compatible with each other. Carnap only says that disputes sometimes vanish when stated this way. There is no explicit claim to the effect that this move by itself makes all ontological disputes go away; nor do I see such a claim being implied.

I mentioned earlier that to have significant consequences for ontology, the basic language pluralist idea must be supplemented by other ideas; and given that Carnap, assuming the language pluralist interpretation, thought that language pluralism had significant consequences, he must have made some such supplementary assumption. Semanticism might be held to amount to one possible such assumption. One possible reason for stressing that there is a multitude of possible languages is that it can then be seen to be plausible that different disputants use different languages. However, as noted, the attribution of semanticism to Carnap is problematic. Moreover, it is not clear how appeal to semanticism could be linked to emphasizing the distinction between internal and external questions.

\section{Quantifier variance}

A thesis which often gets discussed together with the idea that ontological disputes are verbal is that of quantifier variance: the claim that there are different concepts of existence, which all are equally good - there is no metaphysically privileged concept of existence. It is no accident that the theses are discussed together. As mentioned, they were both brought into prominence in the recent metaontological literature by Eli Hirsch. And if the thesis of quantifier variance is true, a friend of the idea that ontological disputes are verbal may naturally further suggest that the disputants use

\footnotetext{
32 Carnap (1935), p. 76.

${ }^{33}$ Carnap (1935), p. $76 f$.

34 Carnap (1935), p. 77.
} 
expressions expressing different ones among the different concepts of existence postulated by the thesis of quantifier variance. But clearly, the theses should be distinguished. For example, even if my critical points concerning verbal disputes are sound, they in no way impugn the thesis of quantifier variance.

However, an important qualification must be made. While some of Hirsch's statements of the thesis of quantifier variance suggest the thesis characterized in the text - and while the quantifier variance thesis characterized in the text is what is discussed by other theorists, such as Chalmers (2009), Hawthorne (2006), Eklund (2007, 2009), and Sider (2007, 2009), it isn't at all clear that this thesis is what Hirsch actually has in mind by 'quantifier variance'. For example, in his (2008), Hirsch says the following:

...the deeper reason for bringing in the imagined communities is to illustrate the possibility of "quantifier variance". It often seems that an implicit assumption of revisionary ontology is that there is only one possible use of quantifier-like expressions in any languages. If that were so, a charitable interpretation of the quantifiers in our language might become moot. By considering the different imagined communities, consisting of non-philosophers who make assertions corresponding to the different ontological positions, we see that the assertions in all these communities are true. The ostensible disputes between these non-philosophical communities are merely verbal. That suffices to defend the commonsensical assertions made by the nonphilosophers in our community. ${ }^{35}$

Here Hirsch seems to understand "quantifier variance" simply to amount to the claim that people can use "there is" and "exists" as his imagined communities do, and same-sounding sentences they employ mean different things. There is no call to ask about existence-like meanings, etc. Maybe we should interpret speakers of other communities as meaning something quite un-existence-like by "there is". That doesn't matter to the "quantifier variance" thesis here described. For as far as this thesis is concerned it isn't the similarity between the meanings that is important; what is important is that people using 'there is' in the ways envisaged by Hirsch would mean different things. If that is all we mean by "quantifier variance" then much of what I say about quantifier variance in the main text is false. The reason for focusing on quantifier variance as characterized is that this is an importantly different thesis from semanticism, and one that has attracted considerable attention in the literature. Perhaps one might call quantifier variance as I introduced it strong quantifier variance, and quantifier

${ }^{35}$ Hirsch (2008), p. 513. 
variance as Hirsch now tends to make clear that he understands it is weak quantifier variance. When speaking of quantifier variance unqualified, it is the strong thesis I will have in mind. ${ }^{36}$

The thesis of quantifier variance faces some immediate troublesome questions. What does it mean to say that there are different concepts of existence? Not that there are different concepts that could be expressed by the string of symbols 'exists', for that would be trivial. Nor, I take it, that there are different concepts that could be expressed by this string of symbols while it means what it actually means. There is only one concept this string could express while meaning what it actually means. (A complication is if 'exists' is somehow semantically indeterminate, but Hirsch does not purport to rely on any such claim.) It is not obvious how this dilemma can be evaded. Hirsch (2002) gestures toward the idea that what unifies the different concepts of existence is their inferential behavior: they satisfy the same rules of inference. But this runs up against the fact that if two expressions in the same language both satisfy the standard inference rules for the existential quantifier, then they are provably equivalent. ${ }^{37}$ This, together with the assumption that the supposed different concepts of existence should be able to cohabitate in the same language, leads to contradiction. (I do not here want to press this objection against quantifier variance. There may be good replies. The point is just to highlight some of the more obvious initial questions that arise.)

Did Carnap believe in quantifier variance? The reason for thinking so would be that the different languages (or frameworks) he discussed would have to be thought of as employing different quantifiers, in the sense of the thesis of quantifier variance. But, first, it is not clear why Carnap would need anything more than the weak thesis of quantifier variance. And a further complication is this. When Carnap discusses different frameworks, he doesn't explicitly discuss two frameworks each with tools for referring to and quantifying over numbers but such that "there are numbers" is true in one and false in another, and "there are" expresses existential quantification in each. Rather, the only framework he discusses with such tools is a platonist framework; a framework within which "there are numbers" comes out true. He does also discuss what a nominalist would say, but discusses only a nominalist who denies that seeming names of numbers are genuine names. It is consistent with everything Carnap says that he would also allow a nominalist framework where quantification over numbers is allowed, but such that "there are no numbers" simply comes out true in that framework. However, the text suggests the different view that in every language where quantification over numbers is allowed, such quantification is successful. The choice between frameworks is not a choice between a framework where quantification over numbers is allowed and successful and one where such quantification is allowed but unsuccessful; it is rather a choice between on the one hand

${ }^{36}$ For more on these matters, see my (2011) review of Hirsch's (2011).

${ }^{37}$ See e.g. Williamson (1987-8). 
adopting a framework where quantification over numbers is allowed and successful, and on the other simply not allowing quantification over and reference to numbers.

Even if Carnap does not subscribe to (strong) quantifier variance, he arguably, if he is a language pluralist, holds a view related to quantifier variance: a view according to which there simply are platonist languages and nominalist languages and that's it - any claim to the effect that platonism or nominalism is somehow objectively privileged is bound to be mistaken. In other work (2009), I have presented a problem for this idea. Briefly, the problem is this. What sort of language is Carnap himself supposed to be using when expressing his view on the nominalist/platonist dispute? To see that there is a problem here, suppose Carnap were using a nominalist language. How could he, using this language, say both that the characteristically platonist sentences of the platonist language are (by his lights) true and that they are genuinely platonistic? He can maybe interpret them as true, by interpreting them as really not ontologically committing. But any such interpretation fails to yield that the supposedly platonist language is platonist. In his contribution to this volume, Richard Creath purports to respond to this argument on Carnap's behalf. But he seems not to have appreciated the exact form of the argument. First, he insists, purportedly as agaist me, that Carnap is not committed to the idea of a universal metalanguage - but it is not part and parcel of my argument to insist that he is so committed. (One may, perhaps, suspect he does needs a universal metalanguage to state his philosophical views; but I don't rely on this claim.) Second, Creath points to how the nominalist can interpret the platonist's sentences such that they come out true. But even so, he fails to note that interpreted as he suggests those sentences, and the language of which they are part, can no longer be described as platonist. ${ }^{38}$

Like semanticism, quantifier variance can be seen as one view on ontology building on language pluralism. The idea is that there is a plethora of different possible languages whose quantifiers have different meanings. But, again as in the case of semanticism, it is not plausible that Carnap subscribed to the idea of quantifier variance. All this goes back to the question of contemporary relevance of Carnap's external/internal distinction. It may be suggested that semanticism and quantifier variance go along with language pluralism, and that there accordingly is some sort of connection. But the connection is rather tenuous, for language pluralism is not itself a very controversial idea. There would be a closer connection between Carnap and the contemporary discussion if there were significant similarities in the use made of the language pluralism, but no such significant similarities have been found.

\section{Naturalness}

${ }^{38}$ Creath (this volume), p. 5 of ms. 
Given the way the debate over the thesis of quantifier variance is conducted, the dispute is between the quantifier variantist, who believes in a multitude of equally good quantifier meanings, and the ontological realist, who believes in a unique best quantifier meaning. ${ }^{39}$ An immediate question is what the goodness of a meaning - or, specifically, of a quantifier meaning - comes to. The standard way to spell it out is: a meaning is good to the extent that it is natural, or fundamental, or joint-carving.

Carnap did not explicitly talk that about this; any claim about what Carnap would say about naturalness will have to be speculative. One immediate and straightforward speculation is that for Carnap, naturalness would be a metaphysical notion; and it is then just nonsense to speak of one meaning as more natural than another. This, however, does not automatically make Carnap a quantifier variantist. For he can still deny that there even is a multitude of quantifier meanings.

A second speculation is this. (I don't find it plausible myself, but I should mention it for completeness.) In an earlier quoted passage from his (1950), Carnap says, to repeat,

I cannot think of any possible evidence that would be regarded as relevant by both philosophers, and therefore, if actually found, would decide the controversy or at least make one of the opposite theses more probable than the other. (To construe the numbers as classes or properties of the second level, according to the Frege-Russell method, does, of course, not solve the controversy, because the first philosopher would affirm and the second deny the existence of the system of classes or properties of the second level.) Therefore I feel compelled to regard the external question as a pseudo-question, until both parties to the controversy offer a common interpretation of the question as a cognitive question; this would involve an indication of possible evidence regarded as relevant by both sides..$^{40}$

The italicized part of this fits poorly with the tenor of the rest of the article. For Carnap otherwise gives the impression that external questions simply have to be pseudo-questions - no ifs and buts about it. But here Carnap seems to suggest that some work could be done, making the external question into something other than a mere pseudo-question. The remark fits so poorly with the rest of the article that one may wish to dismiss it as not seriously meant. But suppose we do take it seriously. What exactly is that that can be done to turn the external question into a cognitive question?

It can be suggested: what theorists like Sider who speak of especially natural or joint-carving meanings appeal to is exactly what is called for here. While talk of what is natural or joint-carving

39 Sider (2009) characterizes ontological realism in the following passage: "there is indeed a single best quantifier meaning, a single inferentially adequate candidate meaning that (so far as the quantifiers are concerned) carves at the joints" (p. 397).

${ }^{40}$ Carnap (1950), p. 219; my emphasis. 
may sound troublingly esoteric, Sider does provide criteria for when a meaning is joint-carving, and the criteria are of the right general kind to satisfy Carnapian scruples: what establishes a meaning as natural is, paradigmatically, an ideological indispensability argument: an argument to the effect that science cannot get by as well without employing an expression with this meaning. If some quantifier is thus indispensable, it is joint-carving.

To stress, I am not endorsing the claim that Carnap would greet Sider's suggestion with approval. What I am saying is precisely only that Sider's suggestion fits the letter of what Carnap is asking for, since the kind of procedure Sider characterizes is one that promises to settle the issues at hand in a suitably scientific manner.

\section{Concluding remarks}

A few concluding remarks may be in order. I first discussed Carnap's internal-external distinctions, his belief in analyticity and his commitment to verificationism and compared the contemporary literature. Then I turned to some ideas from the contemporary metaontological literature semanticism, quantifier variance and the appeal to naturalness - and compared Carnap. The overall conclusion is the one stated earlier. Carnap's importance for contemporary ontology is overstated. Moreover, to the extent that some contemporary themes are found already in Carnap, the contemporary discussions are just as problematic as Carnap's own discussions were.

\section{REFERENCES}

Barnes, Elizabeth: 2009, “Review of David Chalmers, David Manley, Ryan Wasserman (eds.) Metametaphysics: New Essays on the Foundations of Ontology", Notre Dame Philosophical Reviews. Available at http://ndpr.nd.edu/news/24198/?id=17845.

Båve, Arvid: 2011, "How to Precisify Quantifiers", Journal of Philosophical Logic 40: 103-11.

Beebee, Helen, Nik Effingham \& Philip Goff: 2011, Metaphysics: The Key Concepts, Abingdon, Oxon: Routledge.

Bennett, Karen: 2009, “Ontological Anti-Realism”, in Chalmers, Manley and Wasserman (2009). Boghossian, Paul: 1996, “Analyticity Reconsidered”, Noûs 30: 360-91.

Cameron, Ross: 2010, “Quantification, Naturalness and Ontology, in Allan Hazlett (ed.), New Waves in Metaphysics, New York: Palgrave-MacMillan.

Carnap, Rudolf: 1935, Philosophy and Logical Syntax, London: Kegan Paul.

Carnap, Rudolf: 1950, "Empiricism, Semantics and Ontology", Revue Internationale de Philosophie 4: 20-

40. Reprinted with minor changes in Meaning and Necessity: A Study in Semantics and Modal Logic.

Enlarged edition. Chicago: University of Chicago Press (1956).

Chalmers, David: 2009, “Ontological Anti-Realism”, in Chalmers, Manley and Wasserman (2009). 
Chalmers, David, David Manley \& Ryan Wasserman (eds.): 2009, Metametaphysics, Oxford: Oxford University Press.

Creath, Richard: this volume, "Carnap and Ontology: Foreign Travel and Domestic Understanding". Devitt, Michael and Kim Sterelny: 1987, Language and Reality, Cambridge, Mass.: MIT Press.

Dorr, Cian: 2005, “What We Disagree About When We Disagree About Ontology”, in Mark Eli Kalderon (ed.), Fictionalism in Metaphysics, Oxford: Clarendon Press.

Eklund, Matti: 2007, “The Picture of Reality as an Amorphous Lump”, in Ted Sider, John Hawthorne and Dean Zimmerman (eds.), Contemporary Debates in Metaphysics, Oxford: Blackwell. Eklund, Matti: 2009, "Carnap and Ontological Pluralism”, in Chalmers, Manley and Wasserman (2009).

Eklund, Matti: 2011, "Review of Eli Hirsch, Quantifier Variance and Realism”, Notre Dame Philosophical Reviews. Available at http://ndpr.nd.edu/news/24764-quantifier-variance-and-realism-essays-inmetaontology/.

Eklund, Matti: 2013, “Carnap's Metaontology”, Noûs 47: 229-49.

Hawley, Katherine: 2007, "Neo-Fregeanism and Quantifier Variance”, Proceedings of the Aristotelian Society, Suppl. Vol. 81: 233-49.

Hawthorne, John: 2009, "Superficialism in Ontology”, in Chalmers, Manley and Wasserman (2009).

Hirsch, Eli: 2005, "Physical-Object Ontology, Verbal Disputes, and Common Sense", Philosophy and Phenomenological Research 70: 67-97.

Hirsch, Eli: 2008, “Language, Ontology, and Structure”, Nô̂s 42: 509-28.

Hirsch, Eli: 2009, "Ontology and Alternative Languages”, in Chalmers, Manley and Wasserman (2009).

Hirsch, Eli: 2011, Quantifier Variance and Realism, New York: Oxford University Press.

Hofweber, Thomas: 2005, “A Puzzle About Ontology”, Noûs 39: 256-86.

Horgan, Terence: 2001, “Contextual Semantics and Metaphysical Realism: Truth as Indirect Correspondence", in Michael Lynch (ed.), The Nature of Truth, Cambridge, Mass.: MIT Press.

Price, Huw: 2009, “Metaphysics After Carnap: The Ghost Who Walks?”, in Chalmers, Manley and Wasserman (2009).

Priest, Graham: 2006, In Contradiction, New York: Oxford University Press; 2nd edn. First edition published 1987.

Quine, Willard van Orman: 1948, “On What There Is", Review of Metaphysics 2: 21-38.

Sider, Theodore: 2001, Four-Dimensionalism, New York: Oxford University Press.

Sider, Theodore: 2007, "Neo-Fregeanism and Quantifier Variance", Proceedings of the Aristotelian Society, Suppl. Vol. 81: 201-32.

Sider, Theodore: 2009, "Ontological Realism”, in Chalmers, Manley and Wasserman (2009). 
Thomasson, Amie: 2007, Ordinary Objects, New York: Oxford University Press.

Thomasson, Amie: 2007a, "Modal Normativism and the Methods of Metaphysics", Pbilosopbical Topics 35: 135-60. (Actual publication date 2010.)

Williamson, Timothy: 1987-8, "Equivocation and Existence", Proceedings of the Aristotelian Society 88: 109-27.

Wilson, Jessica: 2011, “Much Ado about 'Something': Critical notice of David J. Chalmers, David Manley, and Ryan Wasserman (eds.), Metametaphysics”, Analysis 71: 172-188.

Wittgenstein, Ludwig: 1997, Philosophical Investigations, Oxford: Blackwell. Translated by Elizabeth Anscombe. First published 1953.

Yablo, Stephen: 1998, "Does Ontology Rest on a Mistake?”, Proceedings of the Aristotelian Society, Suppl. Vol. 72: 229-61.

Yablo, Stephen: 2000, “A Paradox of Existence”, in Anthony Everett and Thomas Hofweber (eds.), Empty Names, Fiction and the Purzles of Non-Existence, Chicago: University of Chicago Press. 